\title{
Exploring the Factors Influencing the Performance of District Health Management Teams in Sierra Leone
}

\author{
Alhassan Fouard Kanu \\ E-mail of the corresponding author: allanzain2009@yahoo.co.uk
}

\begin{abstract}
Background: Decentralized district health system is the cornerstone of a country's health sectors. The aim of the present study was to investigate the factors that influence the performance of the district health management team (DHMT) in Sierra Leone. The study was guided by a conceptual framework that is adapted from the World Health Organization leadership and management strengthening framework. Methods: The study used a qualitative method design and targeted both the District Medical Officers (DMO) and their subordinates in four DHMTs (Bo, Kailahun, Kenema and Kono). An interview guide was used to explore the perspectives of both the DMOs and their subordinates $(n=27)$ on the perceived factors that influence the performance of the DHMTs. A thematic analysis, using the WHO framework was carried out in the analysis of the data. Results: The perceived factors that influence the performance of DHMTs are notably the inadequate and late disbursement of funds to the district. This affects the implementation of planned activities. Further, the lack of adequate and capable staff within the DHMTs was highlighted. Other concerns were the poor coordination between national and district level in health program implementation; and the poor working conditions such as poor office spaces, unreliable power supplies and internet connectivity. Conclusions: Addressing the human resource gap within DHMT, ensuring a better flow of funds to the district, and improved coordination in health program implementation between national and district are promising measures that will optimize the performance of the DHMTs in Sierra Leone.
\end{abstract}

Keywords: health system, health system strengthening, health system performance, district health system, district health management, decentralization, devolution

DOI: $10.7176 / \mathrm{JHMN} / 76-03$

Publication date:June 30th 2020

\subsection{Introduction}

The country's health systems performance is a critical element in improving and promoting the health outcomes of its citizens. This is the case for global population health outcomes since there are no longer boundaries that will prevent the spread of diseases within and across borders. The health systems performance of the respective countries in the world has a role to prevent disease spread and ultimately to enhance population health outcomes that is critical for social and economic development.

The district health system is considered as an initial autonomous part of the national health system to provide integrated health services to the population within a specific geographic location (WHO, 1988; Segall, 2003). It is expected that, through an integrated district health system, there will be a wider coverage and more comprehensive health services for the population. The district health system inherently is responsible for the implementation of strategies and activities designed by central-level government to address population health needs. In doing so, various actors are involved including the local politicians, health managers and professionals, civil societies, health-related partners and the beneficiary communities. On the recognition that many key development sectors are represented at the district level, it is considered as the most appropriate level for coordinating top-down and bottom-up planning. The district is also closer to communities and is considered as very strategic for organizing community involvement in both planning and implementation of activities. It has been reported from various country experiences on health service decentralization that, the district is the most appropriate level to support the functions of healthcare providers in terms of providing them with the required supplies, supervision and training (WHO, 1988). Challenges including delays can occur if such support should be provided by national-level authorities (Sakyi, Awoonor-Williams, \& Adzei, 2011). However, concerns have been raised that, most developing countries would find it difficult to achieve the required level of comprehensive health systems. It is admonished that, some of the countries need a strategic reformation on their management and governance practices of their health systems to ensure a degree of comprehensiveness of health service delivery (Segall, 2003).

Whilst developed countries have relatively well-performing and responsive health systems, under-developed nations like Sierra Leone are grappling with challenges that render their health systems largely ineffective with poor population health outcomes. The health sectors of these countries are characterized by weak health system stewardship and funding, inadequate numbers of personnel, poor infrastructure among many other challenges (Cometto \& Campbell, 2016; Lehmann \& Gilson, 2015).

The successful implementation of health activities at district-level is contingent upon a myriad of factors; and some of these factors can facilitate the implementation process while others can hinder the implementation process; both of which influence the level of performance of the DHMT (Sakyi, Awoonor-Williams, \& Adzei, 2011). In 
the implementation of health-related activities, there is often a target or priority population for the given activity as well as an expected result. When both the desired results and the target beneficiaries are not achieved, this signals implementation problems or challenges. This is often as a result of the lack of the critical and relevant factors (include health personnel, funding and materials (such as building, equipment, drugs, utility vehicles and information) for effective implementation (Makinde, 2005). The inadequate or lack of these resources can affect implementation (Makinde, 2005). The staff involved in policy implementation must be adequate in number as well as capable enough to execute their roles. In addition, these staff needs the enabling environment to facilitate their functions; and this involves adequate supplies of working tools, motivation packages including regular wages and guidance and information of policies.

Sierra Leone, as one of the three (3) Mano River Union Ebola viral disease (EVD) affected countries in West Africa in 2014 attributed the weak health system infrastructure and capacity as the principal reasons for the rapid spread of the outbreak (Elston et al., 2015; MoHS, 2015). As part of the response and recovery efforts, a range of health systems strengthening initiatives were instituted to strengthen the country's health system. Some of the initiatives including staff development across a range of discipline, including clinical procedures and health system management. As some facilities were rehabilitated or expanded, inputs were also provided to hospitals and frontline health clinics. These initiatives are expected to enable the health sector to withstand future health shocks, as well as improving the health outcomes of the population. There is a dearth of local knowledge on the extent to which the post Ebola outbreak health system strengthening initiatives have impacted the delivery of primary health services at district level. This study was therefore conducted to explore the factors that influence the performance of DHMT in Sierra Leone. The findings of the study will inform measures to promote the performance of DHMTs and ultimately will improve service coverage, quality and health outcomes of the population

\section{An overview of District Health Management System in Sierra Leone}

Sierra Leone, like many low- and middle-income countries, had reforms on various sectors as initiated in the early 1990s with the support of World Bank and other global agencies. Decentralization was one of the main components of the reforms. Immediately after the 10-year civil war in 2002, series of reforms were made in the country and this includes decentralization of social services such as health. Health service delivery has since become a devolved function to local government authorities. The local councils are responsible for planning, budgeting and managing health services; and this is done in close collaboration with district health managers.

Sierra Leone, a country of an estimated seven million people is situated in West Africa. The country is divided into five administrative regions/provinces and 16 health districts. Health services in the country are provided at three levels of care namely: the community, district and national. This study focuses largely on the district health systems and the emphasis will be limited at this level of healthcare.

The cornerstone of the Sierra Leone health system is the district health system as it is the level of implementation of policies and strategies of the health sector. This level caters for more than $80 \%$ of the country's population; providing both primary and secondary health care; including preventive, curative and promotive health services (MoHS, 2015). There are three levels of healthcare within the Sierra Leone health system namely: Peripheral Health Units (PHU); District Hospitals; and Referral Hospitals. According to MoHS (2015), a total of 1,264 public and private health facilities are distributed across the country to provide health services to the population.

\section{Theoretical Foundation of Study}

This study aims at understanding the factors influencing the performance of district health management teams in Sierra Leone. It is guided by a conceptual framework that is adapted from the World Health Organization leadership and management strengthening framework (WHO, 2007) as illustrated in figure 1. The effective management of health system at all levels requires diverse inputs including well-equipped personnel. The adapted framework from WHO proposes that, four dimensions that encompass all the requisite inputs have to be on a balance to ensure an efficient management of healthcare delivery at the operation level: (1) there needs to be an adequate number of trained managers. (2) Managers need to have appropriate competencies, such as knowledge, skills, attitude and behaviours; (3) critical support systems must be functional and accessible to managers. Such support systems include planning, financial management, information system for decision-making, human resource management (HRM), and management of stocks and assets (e.g. drugs, buildings, vehicles, and equipment); (4) there must be an enabling work environment with regards to roles and responsibilities, supervision and incentives, organisational context and rules, as well as the broad cultural, political and economic context. The framework suggests that strengthening these dimensions can result in more effective health systems and services through an improved and more efficient management (WHO, 2007). All of the four dimensions captured in the WHO framework are determinants of a performing decentralized health system. The chosen framework is a simplified model for illustrating the pathways from health policy and strategy formation to the health service delivery to the population. The choice of this framework is, therefore, considered rational as it aims at 
deconstructing the challenges from a supply side perspective and the relative influence of the dimensions on the performance of health system generally.

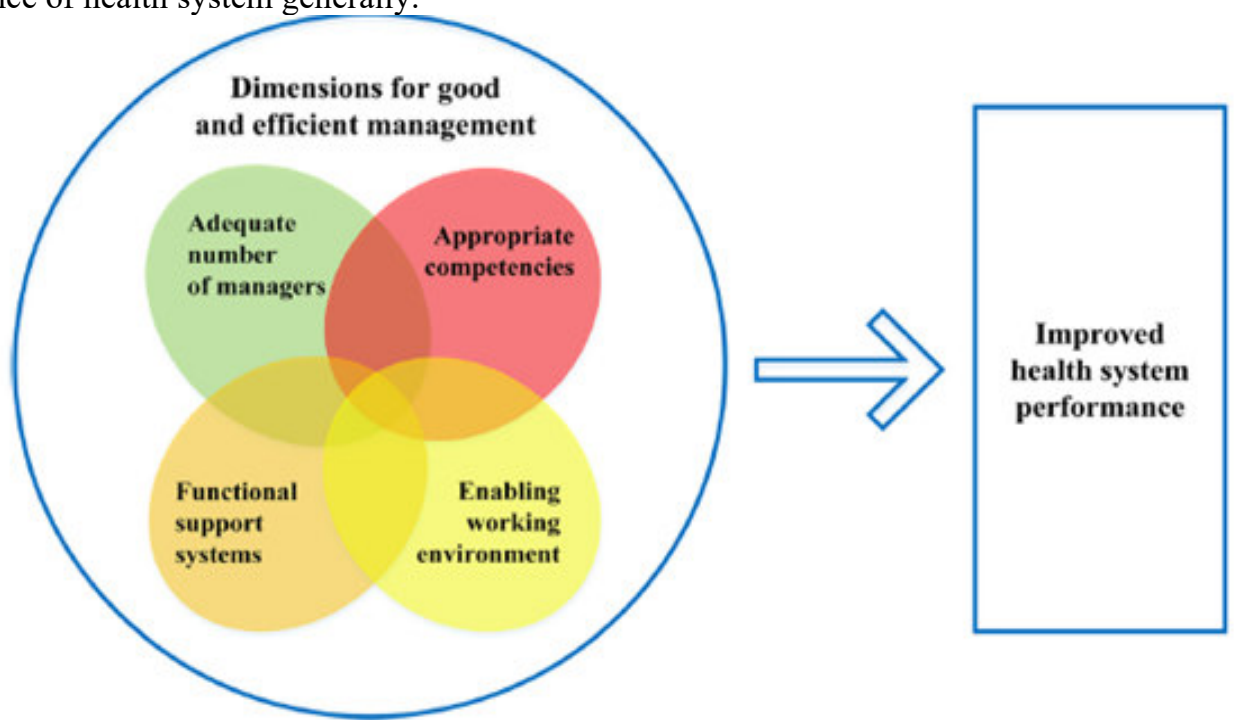

Figure 1: Leadership and Management Strengthening Framework. Adapted from WHO (2007)

\subsection{Materials and Methods}

A qualitative approach was used to explore the inherent factors that can influence the performance of the DHMTs in Sierra Leone. In qualitative research studies, emphasis is placed on verbal description and interpretations rather than statistical analysis of numerical data that can create new concepts and theory (Newman, 2007). This approach offers the possibility of collecting data suitable for an in-depth analysis of the perceived factors that influence the performance of DHMTs in Sierra Leone.

\section{Research Participants}

The target participants for this study were members of the DHMT. To be included in the study, participants must be members of the team; serving a minimum of 1 year as head of a unit or focal person. Members who have spent less than a year and are not heading units within the DHMT are excluded from the study.

\section{Sampling of the participants}

The study considered heads of units at the DHMT. They are purposively selected because of their knowledge on the operations of the DHMT; and hence, can provide the needed information to discern the factors that influence the performance of the DHMT. In this study, a total of seven (7) heads of the most relevant units in the operations of the DHMT were selected in each study district. They are: (1) the District Medical Officer (2) District Health Sister; (3) Monitoring \& Evaluation (M\&E) Officer; (4) Human Resources Officer; (5) District Logistics Officer; (6) Disease Surveillance Officer; and (7) Finance Officer. The study therefore targeted a total of 28 DHMT officials in four districts that participated in the study.

\section{Study Setting}

There are 16 DHMTs in Sierra Leone representing the 16 health districts in the country. For this study, only four (4) districts (Bo, Kailahun, Kenema, and Kono), drawn from 2 of the 4 regions in the country were purposively selected. These districts represent both high performing and low performing districts in the 2018 integrated supportive supervision (MoHS, 2018). The choice of both high and low performing districts will provide insights on whether these districts face similar challenges and what causes the difference in performance.

\section{Data Collection Procedures}

Questionnaires were used to obtain pertinent information from the selected DHMT members on their perceived factors that influence the performance of their team DHMT. The questionnaire was a semi-structured information guide that was researcher-administered. The questionnaire was designed to generate insights on the factors that influence the operations and performance of the DHMT. Prior to conducting the interviews, the heads of the DHMT i.e. the District Medical Officers (DMO) were contacted to discuss the purpose of the study and to seek their consent for the study to be conducted within their teams. Further, the targeted respondents within the respective DHMTs were contacted to seek their willingness to participate after they have read and understood the study information sheet. Interview date and time were agreed upon with the various respondents after agreeing to 
take part in the study. All interviews were conducted by the researcher and his team in locations that were convenient for the respondents. The interviews were conducted in English and they were recorded, using digital audio recorder and/or note-taking. Interviewees' consent was sought for the recording of the interviews. The data collection process lasted for a period of one month (April-May 2019).

\section{Data Processing and Analysis}

All interview tapes were transcribed verbatim and a thematic framework method analysis conducted. The transcripts were repeatedly read in order to familiarize with the data. The four dimensions from the WHO leadership and management strengthening framework (WHO, 2007) were used as the main themes of the analytical framework. Data were entered into Microsoft Word and key themes identified.

\section{Ethical Considerations}

Data collection commenced after review and approval of research protocols by the Sierra Leone Ethics \& Scientific Review Committee (SLESRC). Participants were not forced to participate and were given the right to withdraw from the study at any stage of the interview without prejudice or penalty. To ensure anonymity, each study participant was assigned a code that corresponded with his or her DHMT and only placing the participant's number on the questionnaire, scoring, and code sheets.

\section{Results}

\section{Characteristics of the study districts}

As seen in table 1, Kenema district has the highest population and Kono district has the least population. With regards the health facility distribution, Bo has the highest number of health facilities $(n=138)$, and also the highest number of hospitals $(n=7)$. Kenema follows in terms of both the total number of health facilities $(n=126)$ and the number of hospitals $(n=4)$. This is largely due to the fact that, the Bo and Kenema districts are regional head quarter towns for the Southern and Eastern Regions respectively.

Table 1: Populations and distribution of health facilities in the study districts

\begin{tabular}{|c|c|c|c|c|c|c|c|}
\hline District & $\begin{array}{c}\text { Population } \\
\text { (SSL, 2017) }\end{array}$ & \multicolumn{3}{|c|}{ Distribution of Health Facilities (MoHS, 2017) } & $\begin{array}{c}\text { Total facilities } \\
\text { per district }\end{array}$ \\
\hline Bo & 574,201 & 7 & 34 & 27 & 65 & 5 & $\mathbf{1 3 8}$ \\
\hline Kailahun & 525,372 & 2 & 8 & 43 & 14 & 4 & $\mathbf{7 1}$ \\
\hline Kenema & 609,873 & 4 & 26 & 29 & 63 & 4 & $\mathbf{1 2 6}$ \\
\hline Kono & 505,767 & 1 & 15 & 13 & 54 & 7 & $\mathbf{9 0}$ \\
\hline
\end{tabular}

\section{Characteristics of study participants}

The study targets a total of 28 participants in the 4 districts; comprising of the DMO $(n=1)$ and subordinates $(n=6)$ in each district. As shown in table 2, the response rate for the DMO is $100 \%$ whilst that of the subordinates is $96 \%$ ( 23 out of 24 participants); and the overall response rate of the study is $96.4 \%(n=27)$. The missing participant among the subordinates was due to eligibility reason, as the staff is newly transferred to the Kono DHMT and failed to meet the criteria of a minimum 1 year with the DHMT.

Table 2: Distribution of participants and response rate

\begin{tabular}{|lr|ccc|}
\hline \multicolumn{2}{|c|}{ Category of Participant } & $\begin{array}{c}\text { Target } \\
\text { participants }\end{array}$ & $\begin{array}{c}\text { Response } \\
\text { Received }\end{array}$ & $\begin{array}{c}\text { Response Rate } \\
\text { (\%) }\end{array}$ \\
\hline District Medical Officers (DMO) & 4 & 4 & $100 \%$ \\
$\begin{array}{l}\text { Subordinates } \\
\text { Managers) }\end{array}$ & Total & 24 & 23 & $96 \%$ \\
\hline
\end{tabular}

Table 3 provides the background of the participants. The majority of the participants are male, accounting for $78 \%(n=21)$ of the participants. No female representative among the DMOs in the four districts. Most of the study participants are in the age bracket 36-45 years, accounting for $48 \%(n=13)$ of the participants. With regards the highest level of education, 3 out of 4 DMOs have postgraduate qualification in Public Health; whereas only 4 out of 23 subordinates have postgraduate degrees. Majority of the participants (37\%) are certificate/diploma holders in different professional areas such community/public health, finance, logistics, and pharmacy; whilst 33\% have bachelor's degree. On the length of service in the Ministry of Health \& Sanitation, nearly half of the participants (44\%) have spent 6-10 years in the organization; with a mean duration of 9.87 years. Among the participants, $41 \%$ 
$(n=11)$ have no pin-codes. This suggests that, some of the personnel are either on contract or in a volunteering role; and are awaiting absorption into the civil service.

Table 3: Background of Study Participants

\begin{tabular}{|c|c|c|c|}
\hline \multirow[t]{2}{*}{ Characteristics } & $\begin{array}{l}\text { District Medical } \\
\text { Officers }(n=4)\end{array}$ & $\begin{array}{c}\text { Subordinates } \\
(n=23)\end{array}$ & \multirow{2}{*}{$\begin{array}{c}\text { Totals }(n=27) \\
\text { n }(\%)\end{array}$} \\
\hline & $\mathbf{n}$ & $\mathbf{n}$ & \\
\hline \multicolumn{4}{|l|}{ GENDER } \\
\hline Male & 4 & 17 & $21(78)$ \\
\hline Female & 0 & 6 & $6(22)$ \\
\hline \multicolumn{4}{|l|}{ AGE } \\
\hline $26-35$ & 1 & 6 & $7(26)$ \\
\hline $36-45$ & 2 & 11 & $13(48)$ \\
\hline $46-55$ & 1 & 6 & $7(26)$ \\
\hline \multicolumn{4}{|c|}{ HIGHEST LEVEL OF EDUCATION } \\
\hline Certificate/Diploma & 0 & 10 & $10(37)$ \\
\hline Bachelors & 1 & 9 & $10(37)$ \\
\hline Masters & 3 & 4 & $7(26)$ \\
\hline \multicolumn{4}{|l|}{ YEARS OF EMPLOYMENT } \\
\hline $1-5$ years & 1 & 7 & $8(30)$ \\
\hline $6-10$ years & 2 & 10 & $12(44)$ \\
\hline $11-15$ years & 1 & 2 & $3(11)$ \\
\hline $16-20$ & 0 & 2 & $2(7)$ \\
\hline 20 years and above & 0 & 2 & $2(7)$ \\
\hline \multicolumn{4}{|l|}{ PIN-CODE STATUS } \\
\hline Staff with Pin Code & 4 & 12 & $16(59)$ \\
\hline Staff without Pin Code & 0 & 11 & $11(41)$ \\
\hline
\end{tabular}

\section{Study overall findings}

To generate insights on the factors that influence the operations and performance of the DHMT, a semi-structured and researcher-administered information guide was used. Both the DMOs and their subordinates were interviewed using the same information guide. The main themes of the analytical framework for this study are the four dimensions from the WHO leadership and management strengthening framework (WHO, 2007). These are (1) adequate number of managers (2) appropriate competencies (3) Functional support systems and (4) Enabling environment.

Details of the qualitative findings are presented below:

\section{Adequate number of managers}

In all the district surveyed, human resource was a critical challenge. The issue affects all levels including the frontline health workforce and the DHMT managers. It is expected that, to be a member of the DHMT, an official should be a graduate professional with experience at frontline healthcare management. What was widely reported in the respective districts is the limited number of staff with the requisite knowledge and skills within the teams. The shortage of the required staff at the DHMT level has to do with the embergo of new employments of staff in the health sector, especially for non-clinical staff, as a measure to reduce the burden on the wage bill on government expenditure. As a consequence, some of the staff have to anchor more than one role within the DHMT which ultimately will affect their performance.

"My principal role is M\&E Officer but I double as the HR Officer in the district. It is sometimes challenging for me to effectively address the issues for the respective roles" (M\&E Officer, District 2)

"Of course I agreed to serve in other role(s) in addition to my primary function. However, I often prioritize my primary responsibilities to ensure I satisfy my reporting line at national level before considering those additional roles" (Surveillance officer, District 1).

"I am willing to fill the gap for other roles as requested by the DMO. The problem though is the lack of incentive to compensate for the additional responsibilities. I must be honest; this is what affects our motivation and performance" (M\&E Officer; District 3)

It appears that, the senior managers in the DHMTs notably the DMO and DHS have to rely on passing some of the duties to junior staff to enable them to address to other strategic roles. Doing so have some challenges however.

"The work is too much and as the head, I rely on delegating to other team members. The problem however is the commitment of other staff. Some are weak to execute delegated responsibilities and often you will end up re-working on assigned duties for quality" (District Medical Officer, District 1) 


\section{Appropriate competencies}

It was evident that, the shortage of staff within the DHMTs forced personnel to take roles other than those that they were actually recruited for. This means, the quality of their outputs will be negatively affected; as they are carrying out tasks that they were neither trained for nor having the required experience on. For instance, in one of the district, the Data Clerk was requested to act as the HR Officer. The staff reported that, the additional role is posing serious challenges in performing his primary functions.

"I am not a trained HR Officer; I am the current Data Clerk but I was asked to act as HR Officer following the transfer of the substantive officer to national office. I am still learning on the job and I must attest, I am finding it difficult to address issues of staff in the district" (Acting HR Officer, District 1).

All the DMOs in the four districts acknowledged the lack of appropriate competencies in their teams. They reported that, some of the staff that are posted to the DHMTs lack the professional background, training and experience to support in driving their vision. This is noted as a key barrier to DHMT performance.

"I must confess, some of the staff are very weak to support in the implementation of planned activities. As a DMO, I had to go the extra mile to often develop proposal and concept notes to access funds for planned activities. You have to support even the report writing and liquidations of implemented activities as the weak capacity of the staff often slows progress" (District Medical Officer - District 2)

"As a DHS, I am professionally trained as a nurse midwife. My current role is largely administrative and management. I have not had any formal and in-depth training in administration and management of resources, including health staff" (District Health Sister, District 1)

"We find it difficult with our support staff (e.g. the finance and logisticians). They are people who never had university level training in these areas. They are holding us back when it comes to prudent financial management for example, affecting liquidation processes and accessing funds” (District Medical Officer, District 2).

The success of organizations hinges largely on effective planning. It was reported by some participants that, the poor planning at DHMT affects implementation and reporting.

"As a team, one of our challenges is to develop and implement plans. Many a time, plans are not developed on time nor fully implemented. The lack of a coherent planning arrangement between national and DHMT often affect our implementation in the district" (Finance Officer, District 2).

\section{Functional support systems}

There is no gainsaying that the efficiency of DHMT is partly contingent upon how well critical support systems function. A range of management systems are at the exposure of DHMTs in Sierra Leone and notably include HR, planning, finance, transportation, and distribution of drugs and medical supplies. The commonest that centred the responses of the participants is the financial constraints. Notwithstanding, issues around other systems such as lack of vehicles for monitoring and supervision of activities, HR challenges were also reported.

On the financial constraints of the DHMTs, it was reported that the funding from national government always come late and often inadequate to implement the planned activities. In addition to affecting implementation, the late release of funds also affects operations; such as vehicle and office operation; and hence undermine the performance of the DHMTs. It is widely reported by all DMOs that, they often rely on partners support and vertical programs to run the DHMT and implementing vital and life-saving interventions in the districts.

"Our operations are seriously undermined by the lack of funds at the DHMT. We hardly received funds on time. For example, this is the second quarter of the year and we have only received the first quarter. So how could one expect us to deliver activities as planned?" (District Medical Officer-District 3).

"When we presented our annual budget to national and local council, it will surprise you to know that, we often end up receiving only three-fourth of the estimated amount. This inherently affects the quality of our services and the poor performance of the district" (District Medical Officer-District 2).

The health sector is a devolved function to the local authority and funds for the operations and activity implementations are passed through the local councils. The DHMTs acknowledge the relative easier access to the funds in comparison to national level structures. However, some challenges were mentioned by every DMO and Finance Officers.

"Decentralization also poses serious challenges in accessing funds for DHMT operations. There are lots of bureaucratic challenges that affect timely and adequate release of funds" (District Medical Officer, District 1)

\section{Enabling environment}

On the discussions of the enabling environment for DHMT operations, it was widely reported by the participants that the inadequate planning and communication especially at national level is considered as a major hindrance on DHMT operations. The relationship between national and district in terms of coordination is affecting the work of DHMTs as reported. 
"As a DHMT, we are answerable to national authorities and in many occasions, our agenda is displaced to accommodate the priorities of national programmes and directorates" (District Medical Officer, District 4)

“...what is most concerning is the late notifications for workshops and trainings. This often requires us to travel to the capital city Freetown to participate in this function; and hence our planned activities are left unattended" (District Medical Officer, District 3)

"Undoubtedly our inputs are required in the development of health sector strategies and policies at national level. It is however important that national level coordinate such activities well to enable us carry out our own duties in the district" (District Medical Officer-District 2).

The DMOs overwhelmingly reported that, what they have can best be described as "deconcentration" and not "decentralization" of health functions. According to the participants, functions that have to do with staff recruitment and deployment, for example, are still been managed by national. The fact that some of the planning that should otherwise be done by DHMTs are conducted at national are perceived as affecting district operation. According to the participants, the distribution of drugs and medical supplies should be informed by district needs. This is not currently the case as national "pushes" supplies to the district.

"In the district, we are challenged with providing the needed drugs and supplies to our health facilities. This is because of the push system, where national send out drugs without consultations with the district stores. As a result, most of the items are not needed and this accounts for the frequent stock-outs of essential supplies (District Logistics Officer, District 1).

Others reported concerns with regards the enabling environment for operations include the lack of reliable power supplies, and internet connectivity at the DHMT offices. Some reported the lack of convenient office spaces as a problem.

"As you can see, our office is very small to accommodate us for two district health sisters. We are really constrained here and it affects our performance" (District Health Sister, District 1).

"Many a time, we are blamed for not sending report to national on time. But as you can see, we have poor electricity supplies and no internet connection. This is a big concern for our operation in the $M \& E$ unit (M\&E, District 3)

\subsection{Discussions, Conclusions and Recommendations}

Lots of factors are seemingly responsible for an effective performance of decentralized health system. In the current study, both district health managers and their subordinates were interviewed to explore their perceptions on inherent factors that undermine the performance of the DHMTs in Sierra Leone. The study revealed that, DHMTs are short of the requisite staff to carryout routine activities. It was evident in the respective districts that staffs have to anchor other roles in the absence of other staff. In some districts, the M\&E Officers, for example are also acting as HR Officers. This has serious implications on the outputs of staff and inherently on the performance of the DHMT. Health systems in sub-Saharan countries are grappling with human resource as a key severe constraints for increased access to effective health care delivery. The findings of the current study corroborate with many others in counties like Uganda (Henriksson et al., 2017); and Ghana (Bonenberger, Aikins, Akweongo, \& Wyss, 2016). These countries, like Sierra Leone recognized human resource gap as the biggest bottleneck for effective health services delivery.

Compounding the problem of staff shortages in the DHMTs is the competencies of the staff. It is expected that, an individual must have accrued a lot of experience and professional qualifications to qualify for DHMT membership. It is however revealed by this study that, some of the staff lacks the necessary skills, training and experience for their positions at the DHMT. The DMOs reported that, they always have difficulties in delegating responsibilities due to the weak capacity of some of the staff; and this leaves them highly burdened with work. Some staff testified over some of the training gaps that undermine their performance. In all the districts visited, the number of staff at the DHMT is apparently large but the capacity and dedication of staff is a challenge; leaving few people to do the job with dire consequences on the team's performance.

There is no gainsaying that the efficiency of DHMT is partly contingent upon how well critical support systems function. A range of management systems are at the exposure of DHMTs in Sierra Leone and notably include HR, planning, finance, transportation, and distribution of drugs and medical supplies. The commonest that centred the responses of the participants is the financial constraints. Notwithstanding, issues around other systems such as lack of vehicles for monitoring and supervision of activities, HR challenges were also reported.

The study revealed that, the DHMTs are grappling with serious financial constraints that affect their ability to implement planned activities. It was reported that the funding from national government through the local councils always come late; and is often inadequate to implement the planned activities. In addition, the late release of funds also affects operations; such as vehicle maintenance and office operation. The constraints in the timely accessing of funds as reported in the current study was also highlighted by the findings of Asante, Zwi, \& Ho (2006) qualitative study in Ghana and by Abekah-Nkrumah, G., Dinklo, T., \& Abor, J. (2009) study on financing 
the health sector, also in Ghana. They reported that, the untimely release funds to sub-national health system disrupt the implementation of health activities. This has the tendency of demoralizing the DHMTs and inherently their performance. It is widely reported by all DMOs that, they often rely on partners support and vertical programs to run the DHMT and implementing vital and life-saving interventions in the districts. This coping strategy is also being employed by health managers in low-income countries with budget constraints for the health sectors; as found by Bonenberger, Aikins, Akweongo, \& Wyss (2016) study.

The World Health Organization (2007) noted that, the existence of factors such as policies, legislation, norms and standard are critical in the appropriate delegation of authority. These factors, according to WHO, are needed to guide and support managers in the access to information, communication, supervision as well as financial and non-financial incentives for good management and accountability. On the discussions of the enabling environment for DHMT operations, it was widely reported by the participants that the inadequate planning and communication especially at national level is considered as major hindrance on DHMT operations. The DMOs generally noted that, what they have can best be described as "deconcentration" and not "decentralization" of health functions. According to the participants, functions that have to do with staff recruitment and deployment, for example, are still been managed by national. Concerns were also expressed on the current approach in the distribution of drugs and medical supplies from national to district. The "push" approach according to the district leadership is not helpful and it often fails to address the needs of their districts. They prefer a "pull" system that gives the opportunity to request for drugs that are actually needed. Others reported concerns with regards the enabling environment for operations include the lack of reliable power supplies, and internet connectivity at the DHMT offices. Some reported the lack of convenient office spaces as a problem.

\section{Conclusions}

This qualitative study has highlighted broad concerns of the DHMTs in Sierra Leone on what is considered as factors responsible for their performance. On the perceived factors that are responsible for the DHMT performance, notable among the reported factors include firstly, financial constraints to manage the operations of the DHMT and the implementation of planned activities. Secondly, the staff shortage and the weak capacity of some of the team members affect the work and the limited staff are overwhelmed with work; having to fill in the human resource gaps. This has implications on the outputs of staff and the overall performance of the DHMT. The study also revealed that, nearly half of the subordinates in the 4 DHMTs are yet to be recruited into the civil service. This suggests that, some of the personnel are either on contract or in a volunteering role; whilst awaiting absorption into the civil service. The implication for having staff on contract or in a volunteering role is poor motivation and retention concerns. Staff leaves when their contracts are not renewed, extended, or for any delay in absorption into the service. This will cause loss of experienced staff with dire consequences on DHMT operations and performance. Further, the weak coordination between national and district levels often disrupt district implementation plans. The poor working conditions of the DHMTs; especially due to lack of proper work spaces, poor internet connectivity and the erratic power supplies affects the work of staff.

\section{Study Limitations}

This study, like many others is not limitation-proof. A notable limitation is the non-inclusion of other relevant stakeholders in the district and national health system. This study made no attempt to explore the perceptions of central leadership of the Ministry of Health \& Sanitation; health-related partners; the local councils; the health service providers as well as the health service-users (patients and communities). A different perspective might have been captured through such triangulation. Despite these limitations, the inclusion of both the DMOs and their subordinates in the study has filled an important gap in the literature. Further, the study findings mirror the concerns and challenges of other DHMTs; considering the context and the broader administrative responsibilities of the DHMT in relation to national health sector governance.

\section{Recommendations}

In view of the findings of this study, the following recommendations are proposed:

1. Increase health sector budget and strengthen fiduciary accountability structures to expedite cash transfers to districts

2. Re-engineer the DHMT structure, ensuring only competent staff with the requisite years of experience are posted to work at DHMT. Clear job description of staff should be provided for a healthy and accountable working relationship

3. Continually strengthen the capacity of DHMTs with the requisite staff in terms of both number and competencies

4. Improve coordination between district and national level in health program implementation

5. Promote cordial working relationship between the district health management system and district councils 


\section{Acknowledgement}

I thank the DMOs of Bo, Kailahun, Kenema, and Kono districts and their staff for participating in the study. My appreciation also goes to the staff of the International Rescue Committee (IRC) working in the 4 districts.

\section{References}

Abekah-Nkrumah, G., Dinklo, T., \& Abor, J. (2009). 'Financing the Health Sector in Ghana: A Review of the Budgetary Process'. European Journal of Economics, Finance and Administrative Sciences;17,pp.45-59

Asante, A.D., Zwi, A.B., \& Ho, M.T. (2006). 'Getting by on credit: How district health managers in Ghana cope with the untimely release of funds'. BMC Health Services Research,6 (105),pp.1-9

Bonenberger, M.,Aikins, M., Akweongo, P., \& Wyss, K. (2016). 'Factors influencing the work efficiency of district health managers in low-resource settings: A qualitative study in Ghana'. BMC Health Services Research;16(12), pp.1-10 doi:10.1186/s12913-016-1271-3

Cometto, G., \& Campbell, J.(2016). 'Investing in human resources for health: Beyond health outcomes'. Human Resource Health; 14:51, pp.1-2.

Elston, J.W.T., Moosa, A.J., Moses, F., Walker, G., Dotta, N., Waldman, R.J., \& Wright, J. (2015). 'Impact of the Ebola outbreak on health systems and population health in Sierra Leone'. Journal of Public Health, 38(4), 673-678. doi:10.1093/pubmed/fdv158

Henriksson, D.K., Fredriksson,M., Waiswa, P., Selling, K., \& Peterson, S.S. (2017). 'Bottleneck analysis at district level to illustrate gaps within the district health system in Uganda'. Global Health Action, 10 (1327256), pp.110 ;

Lehmann, U., \& Gilson, L. (2015). 'Action learning for health system governance: The reward and challenge of co-production'. Health Policy and Planning; 30: 957-963.

Makinde, T. (2005), 'Problem of policy implementation in developing nations: the Nigerian Experience', Journal of Social Science, 11(1), pp. 63-69.

MoHS (2015). Health Sector Recovery Plan (2015-2020). Sierra Leone: Ministry of Health \& Sanitation

MOHS (2018). 2017 Service Availability and Readiness Assessment Report. Sierra Leone, Ministry of Health \& Sanitation

Neuman, W. L. (2007). Basics of social research: Quantitative and qualitative approaches (2nd ed.). Boston, MA: Allyn \& Bacon

Sakyi,E.J., Awoonor-Williams,J.K., \& Adzei,F.A. (2011) 'Barriers to implementing health sector administrative decentralisation in Ghana: A study of the Nkwanta district health management team', Journal of Health Organization and Management, 25(4), pp.400-419, doi:10.1108/14777261111155038

Segall, M.(2003). 'District health systems in a neoliberal world: A review of five key policy Areas'. International Journal of Health Planning \& Management; 18(1), pp.S5-26.

Statistics Sierra Leone (2015). Sierra Leone 2015 Population and Housing Census. Retrieved from: https://www.statistics.sl/images/StatisticsSL/Documents/Census/2015/sl_2015_phc thematic_report_on_po $\mathrm{p}$ structure and pop distribution.pdf

WHO (1988). The challenge of implementation: District health systems for primary healthcare. Geneva: World Health Organization. $\quad$ Retrieved: from https://apps.who.int/iris/bitstream/handle/10665/62369/WHO SHS DHS 88.1 Rev.1.pdf?sequence=1\&is Allowed $=\mathrm{y}$

WHO (2007). Towards better leadership and management in health: Report on an international consultation on strengthening leadership and management in low-income countries, Making health systems work: working paper no 10. Geneva: World Health Organization. 